\title{
Health investment management based on patient satisfaction with the primary care doctor in the Spanish national health service context. a gender perspective
}

\begin{abstract}
Background: To determine which key indicators of the Spanish NHS influence the patient satisfaction with respect to the primary care doctor. In order to help improve the management of the system's financial resources.

Method: A means test was applied to compare the satisfaction of the male patient and the female patient. Subsequently, both satisfaction measures were related, by a multiple linear regression, with 16 explanatory variables, corresponding to each of the 17 Autonomous Communities of Spain, for the period 2005-2016.

Results: The models explained $51.3 \%$ of men's satisfaction with the primary care doctor in the Spanish NHS, and $54.1 \%$ of women's satisfaction the variables with a positive and significant influence were the number of specialists and primary care doctors, the number of CT equipment, the use of hemodialysis equipment and in-hospital mortality. On the other hand, the number of operating theatres, the length of hospital stay, the use of CT equipment and the expenditure on pharmacy influence negative and significantly.

Conclusion: Health policies should increase the number of doctors and specialized treatment and diagnosis equipment, inform the patient about the functioning of such equipment to reduce fear of its use, facilitate hospital treatment, monitor the effectiveness of surgery and moderate the prescription of drugs, facilitating the use of alternative methods. The aim is to increase patient satisfaction.
\end{abstract}

Keywords: health management; quality of health care; patient satisfaction; national health service; primary care doctor; gende
Volume 4 Issue 5 - 2019

\section{María del Carmen Valls Martínez, Isabel María Parra Oller \\ Economics and Business Department, University of Almería, Spain}

Correspondence: María del Carmen Valls Martínez, Senior Lecturer, Economics and Business Department, University of Almería,Spain,Tel +34950015535, Email mcvalls@ual.es

Received: October 20, 2019 | Published: October 24, 2019

\section{Introduction}

Public management of a national health system (NHS) is a major challenge for policy makers. It is due to, on the one hand, the ageing of the population in developed countries, what leads to an increasing demand for health services. And, on the other hand, to the increase in the citizens' expectations, who are increasingly demanding and require higher quality services. All this adds to the increase costs of technology and limited economic resources. ${ }^{1}$ Providing a high service quality is the goal of a NHS, ${ }^{2}$ since the health sector is a sector where low quality has serious consequences. ${ }^{3}$ Quality is a precursor of patient satisfaction and there is a positive correlation between the two, so that more quality implies more satisfaction., ${ }^{4,5}$

Budgetary constraints and the growing number of patients require managers to implement resource allocation policies, which permit to reduce costs and, at the same time, improve the quality of service. This is key to the success of the health industry. ${ }^{6-8}$

At first, quality was limited to ensuring the effectiveness of treatment, but patient satisfaction is now included. ${ }^{9}$ In fact, at the
European Foundation for Quality Management, customer satisfaction (patient, in health) represents $20 \%$ of the total value. ${ }^{10}$ In addition, the International Organization for Standardization considers the opinion of the user essential in the evaluation of the quality of health services. ${ }^{11}$ In general, the patient's opinion on his satisfaction degree is considered a good indicator of the quality of medical care received, ${ }^{12-14}$ and, therefore, of the effectiveness and performance of NHS, ${ }^{15,16}$ It also has the advantage of measuring the improvement in quality, resulting from management decisions taken. ${ }^{17,18}$

Patient satisfaction analyses provide useful information not only to health professionals (doctors, nurses, etc.), but also to NHS managers and administrators. ${ }^{19}$ The quality of service is an increasing key research in management. In particular, the quality of health service, which is more important than any other service, ${ }^{20}$ because of its importance to improve the population health, raise the citizens' life expectancy, contribute to social equity and improve the efficiency of its economy and health system. ${ }^{21}$ Therefore, developing and analysing surveys of satisfaction is a measure of responsibility, as these provide information on developing of future policies. ${ }^{22}$ 
There is a lack of standardization in the methods of measuring patient satisfaction. ${ }^{23}$ This is because the satisfaction of a service, such as health care, is the result of a multidimensional interaction. And the variables considered in the different studies are very diverse. ${ }^{24,25} \mathrm{~A}$ review of the previous literature on satisfaction allowed us to select the main variables, useful for the definition and implementation of health policies. These are indicators of well-being, ${ }^{11,21,26}$ resources of the national health systems, ${ }^{27-30}$ level of use of services offered, ${ }^{1,31-33}$ patient safety in services received ${ }^{34-36}$ and amount of expenditure incurred. ${ }^{11,21,37}$ In addition, considering the current of research on gender in management. ${ }^{38-40}$ we wanted to analyse whether there are differences in the level of satisfaction between men and women. As well, whether the variables that influence satisfaction ${ }^{9,36}$ or its intensity are different according patient sex.

Consequently, the objective of this study was to determine which indicators, among those with available information, influence and in how in the patient satisfaction in the Spanish NHS, differentiating by gender. All this with the aim of providing managers information to improve health in the country.

\section{Method}

The data of the variables used in this study were obtained from the statistical portal of the Ministry of Health, Social Services and Equality of Spain. Here, the averages of NHS key indicators are published for each of the 17 Autonomous Communities, in which the Spanish territory is divided. A period of 11 years was analysed, from 2005 to 2016, being excluded from the study the year 2014, due to the lack of data for this year. Therefore, the analysis was performed with 187 observations for the dependent variable and for each one of independent variables.

The dependent variable studied was the degree of patient satisfaction with knowledge of the history and monitoring of their health problems by the primary care doctor in the Spanish NHS
(Satisf). Given that we had sex-disaggregated data and the averages of men and women satisfaction were different, we decided to see if such a difference was by chance or, on the contrary, was really significant. Consequently, and since the two subsamples (Satisfmen and Satisfwomen) followed a normal distribution, we performed a parametric test to analyse this question.

Then, an analysis of the descriptive statistics of each variable was carried out. And, afterwards, the bivariate Pearson correlation between each independent variable and the dependent variable, disaggregated by gender, was conducted to see the influence of each independent variable on each dependent variable.

The study considered 16 independent variables, whose definition appears in Table 1. In particular, two variables that represent the level of well-being of the population was used: life expectancy at birth (Life Exp) and the poverty rate (Poverty). In addition, it was included five variables that reflect the resources available to the NHS in the Spanish autonomous community where the patient is located: the number of specialist doctors (Spec Doctor), the number of primary care doctors (Prim Doctor), the number of primary care nurses (Prim Nurs), the number of operating theatres (Oper Theat) and the number of computed tomography equipment (CTE quip). Likewise, five variables representing the level of use of NHS by the patient were considered: the number of hospital admissions (Hosp Adm), the average number of days in-hospital stay (Hosp Stay), the percentage of outpatient surgery (Outp Surg), the rate of use of computed tomography equipment (Use CT) and the percentage of use of haemodialysis equipment (Use Hemod). In addition, two variables representing patient safety were considered: hospital infection rate (Hosp Infec) and in-hospital mortality (InHospMort). Finally, two variables representing NHS expenditure in the autonomous community were used: public health care expenditure per inhabitant (Expend) and the percentage of health care expenditure on pharmacy (Exp Pharm) (Table 1).

Table I Definition of variables

\begin{tabular}{|c|c|}
\hline Variable & Definition \\
\hline Satisf & $\begin{array}{l}\text { Degree of patient satisfaction with knowledge of the history and monitoring of their health problems by the } \\
\text { primary care doctor in the Spanish NHS }\end{array}$ \\
\hline LifeExp & Life expectancy at birth \\
\hline Poverty & Poverty rate \\
\hline SpecDoctor & Number of specialist doctors per I,000 inhabitants in the Spanish NHS \\
\hline PrimDoctor & Number of primary care doctors per I,000 inhabitants in the Spanish NHS \\
\hline PrimNurs & Number of primary care nurses per 1,000 inhabitants in the Spanish NHS \\
\hline OperTheat & Number of operating theatres per 100,000 inhabitants in the Spanish NHS \\
\hline CTEquip & Number of Computerized Tomography equipment per 100,000 inhabitants in the Spanish NHS \\
\hline HospAdm & Number of hospital admissions per 100,000 inhabitants in the Spanish NHS \\
\hline HospStay & Average number of days in hospital stay in the Spanish NHS \\
\hline OutpSurg & Percentage of outpatient surgery in the Spanish NHS \\
\hline UseCT & Rate of use of CT per I,000 inhabitants in the Spanish NHS \\
\hline UseHemod & Rate of use of haemodialysis equipment per I,000 inhabitants in the Spanish NHS \\
\hline Hosplnfec & Hospital infection rate per 100 hospital discharges in the Spanish NHS \\
\hline InHospMort & In-hospital mortality per 100 hospital discharges in the Spanish NHS \\
\hline Expend & Health care expenditure per inhabitant in the Spanish NHS \\
\hline ExpPharm & Percentage of health care expenditure on pharmacy \\
\hline
\end{tabular}

Citation: Martínez MDCV, Oller IMP. Health investment management based on patient satisfaction with the primary care doctor in the Spanish national health service context. a gender perspective. MOJ Gerontol Ger. 2019;4(5):204-2II. DOI: I0.15406/mojgg.2019.04.00208 
Once the model was presented with all the above-mentioned indicators, two independent parallel studies were carried out using the multiple linear regression methodology, to explain the satisfaction of the male patient and the female patient through objective and measurable indicators, both from the NHS and from the population. Likewise, two pooled ordinary least squares were conducted, since it was not consistent to apply a panel methodology. This was because the subjects interviewed to obtain the annual averages of each autonomous community were not the same each year. For each sex, men and women, two regressions were performed. In the first one, all the independent variables were considered, applying the method "introduce". In the second one, the "backward stepwise regression" method was used, eliminating from one to one the least significant variables and with significance less than 0.1 . The validity of the models was evaluated from two tests: the ANOVA test, to measure the joint validity of the model, which is appropriate if the $p$ of the $F$ value obtained is $<0.05$; and the Durbin-Watson statistic to verify the residuals normality and to avoid autocorrelation, whose ideal value is 2, although values between 1.5 and 2.5 are considered acceptable. The statistical programme SPSS v. 25 was used for the processing of the data.

\section{Results}

The analysis of the descriptive statistics, in Table 2, showed a greater average satisfaction in women than in men, along with a smaller deviation. This difference in means was significant, since the $p$-value obtained from $t$-test was 0.001 . That is, women are, generally and on average, more satisfied than men with the care and attention provided by their primary care doctor (Table $2 \& 3$ ).

Table 2 Descriptive statistics

\begin{tabular}{lllll}
\hline Variable & Minimum & Maximum & Mean & Standard deviation \\
\hline Satisf Men & 618 & 826 & 731.97 & 43.01 \\
SatisfWomen & 638 & 839 & 746.24 & 42.21 \\
LifeExp Men & 75.69 & 84.2 & 79.59 & 1.73 \\
LifeExp Women & 82.12 & 87.83 & 85.49 & 1.19 \\
Poverty & 5.3 & 40.2 & 20.04 & 7.66 \\
SpecDoctor & 1.23 & 2.14 & 1.67 & 0.21 \\
PrimDoctor & 0.59 & 1.1 & 0.77 & 0.11 \\
PrimNurs & 0.47 & 0.9 & 0.65 & 0.1 \\
OperTheat & 4.3 & 8.97 & 6.3 & 0.94 \\
CTEquip & 0.64 & 1.75 & 1.1 & 0.24 \\
HospAdm & 55.55 & 126.77 & 91.51 & 15.06 \\
HospStay & 5.15 & 7.24 & 6.08 & 0.44 \\
OutpSurg & 17.52 & 59.1 & 40.91 & 8.52 \\
UseCT & 21.64 & 113.32 & 68.82 & 15.6 \\
UseHemod & 0 & 67.54 & 32.99 & 11.99 \\
Hosplnfec & 0.89 & 1.67 & 1.21 & 0.16 \\
InHospMort & 2.98 & 5.64 & 4.28 & 0.62 \\
Expend & $1,026.24$ & $1,883.52$ & $1,400.69$ & 171.77 \\
ExpPharm & 12.91 & 29.52 & 19.5 & 3.24 \\
\hline
\end{tabular}

Table 3 Difference in the value of the dependent variable (T-test)

\begin{tabular}{lll}
\hline Mean men's satisfaction & Mean women's satisfaction & Difference $^{(+)}$ \\
\hline 731.9732620 & 745.2406417 & $14.2676797^{\text {**** }}(0.001)$
\end{tabular}

(+) p-value in parentheses.

***, $* *$ and $*$ indicate less than $1 \%$ significance level, less than $5 \%$ and less than $10 \%$, respectively.

Likewise, between 2005 and 2016, the average life expectancy in the different autonomous communities was 85.49 for women and 79.59 for men. That is, women have a life expectancy of 5.9 years, on average, higher than men.
With regard to the poverty rate, the other indicator of well-being taken together with life expectancy, it was observed a great difference among the different regions of the country. We find that the poorest communities are those located in the southern half of the country, whereas the most prosperous are in the north. 
The health personnel of Spanish NHS, per 1,000 inhabitants, were on average, during the period under consideration and for the different autonomous communities, 1,67 specialist doctors, 0.77 primary care doctors and 0.65 primary care nurses. While the average number of operating theatres and CT equipment was 6.3 and 1.1, respectively. In addition, it is observed that, all the representative variables of available resources presented important differences between north and south communities again. Generally, the northern communities have more available resources.

Similarly, the level of use of health resources and services showed significant variations among the different regions of the country. It is emphasized that, for every 100,000 inhabitants, the average annual number of hospital admissions was 91.51 and the average stay of admissions 6.08 days. The safety variables analysed showed that, for every 100 hospital discharges, the average infection rate was $1.21 \%$ and the in-hospital mortality rate was $4.28 \%$.

Finally, the average total expenditure on the NHS per inhabitant was very different in the Spanish territory, varying between 1,026.24 euros and 1,883.52 euros. This is a consequence of the transferring of sanitary competences to the autonomous communities, what leads to an obvious inequality among regions within the country. Likewise, there are also important differences in health policies, as shown the differences in the percentage of the health budget allocated to medicine, varying between 12.91 and 29.52 per cent. We note that the richest communities, northern, are those which spend a lowest percentage of total investment, on average, on medicine.

Most of the variables showed a significant correlation with satisfaction, both in men and women, having a fairly similar behaviour in both cases. The five variables representative of resources were positively correlated with male and female satisfaction. Four of the five NHS use variables analysed behaved in the same way, although the length of the hospital stay showed a negative correlation. That is, the greater the resources available and the greater the use made of them, the greater the satisfaction of the patient is; and, the longer the hospital stay, the lower the satisfaction is (Table 4).

Table 4 Pearson's correlation coefficients between indicators and patient satisfaction

\begin{tabular}{|c|c|c|c|c|c|c|}
\hline \multirow{2}{*}{$\begin{array}{l}\text { Variables } \\
\text { LifeExp Men }\end{array}$} & \multicolumn{3}{|c|}{ Men's satisfaction } & \multicolumn{3}{|c|}{ Women's satisfaction } \\
\hline & + & low $(0.366)$ & $* *$ & & & \\
\hline LifeExp Women & & & & + & low $(0.392)$ & $* *$ \\
\hline Poverty & - & low $(0.206)$ & $* * *$ & - & very low $(0.161)$ & $*$ \\
\hline SpecDoctor & + & moderate $(0.50 \mathrm{I})$ & $* * *$ & + & moderate $(0.521)$ & *** \\
\hline PrimDoctor & + & low $(0.263)$ & $* * *$ & + & low $(0.295)$ & **a \\
\hline PrimNurs & + & low (0.339) & **a & + & low $(0.377)$ & $* *$ \\
\hline OperTheat & + & low (0.364) & *** & + & low $(0.342)$ & $* *$ \\
\hline CTEquip & + & moderate $(0.427)$ & $* * *$ & + & moderate $(0.456)$ & **a \\
\hline HospAdm & + & low $(0.306)$ & *** & + & low $(0.32 \mathrm{I})$ & ${ }^{* * *}$ \\
\hline HospStay & - & low $(0.388)$ & $* * *$ & - & low $(0.307)$ & *** \\
\hline OutpSurg & + & low $(0.253)$ & $* * *$ & + & low $(0.270)$ & $* * *$ \\
\hline UseCT & + & low $(0.3 \mid 8)$ & **ak & + & low (0.289) & $* *$ \\
\hline UseHemod & + & low (0.353) & $* * *$ & + & low $(0.363)$ & $* * *$ \\
\hline Hosplnfec & - & very low $(0.040)$ & & & very low $(0.044)$ & \\
\hline InHospMort & + & very low (0.119) & & + & low $(0.174)$ & $*$ \\
\hline Expend & + & low (0.348) & $* * *$ & + & low (0.308) & *** \\
\hline ExpPharm & - & moderate $(0.540)$ & $* * *$ & - & moderate $(0.508)$ & $* * *$ \\
\hline
\end{tabular}

Number of observations, 187

Correlation sign: positive, + ; negative, - .

Intensity of correlation: null, 0 ; very low, $0.0 \mathrm{I}-0.19$; low, $0.2-0.39$; moderate, $0.4-0.69$; high, $0.7-0.89$; very high, $0.9-0.99$; perfect, I.

Significance level: $* * *, p<0.01$; **, $0.01<p<0.05$; $* 0.05<p<0,10$; if $p>0.10$ nothing is indicated.

One of the two variables analysed representatives of the level of well-being, patient safety and NHS expenditure showed a positive correlation with patient satisfaction with respect to the primary care doctor, while the other behaved negatively. In particular, the variables of life expectancy, in-hospital mortality and health care expenditure per inhabitant showed a positive correlation with patient satisfaction. On the contrary, the poverty rate, the hospital infection rate and the percentage of health care expenditure on pharmacy were inversely related to the degree of patient satisfaction. The only variable that was not significant, at the level of correlation, neither for the men satisfaction nor for women satisfaction was the hospital infection rate.

The multiple linear regression analysis performed showed a similar tendency when all variables were considered together and when the backward stepwise method was applied, for both men and women satisfaction (Tables $5 \& 6$ ). Likewise, there were no significant differences between the sexes. These models explained $51.3 \%$ of men's satisfaction with the primary care doctor in the Spanish NHS, and $54.1 \%$ of women's satisfaction. 
Table 5 Men's satisfaction: regression analysis (OLS estimation)

\begin{tabular}{|c|c|c|c|c|c|c|}
\hline \multirow[b]{2}{*}{ Variables } & \multicolumn{3}{|c|}{ Enter method } & \multicolumn{3}{|c|}{ Backward method } \\
\hline & $B$ & $p$ & Confidence interval & $B$ & $p$ & Confidence interval \\
\hline Constant & $1,067.123^{* * *}$ & 0.000 & $(737.852 ; 1,396.394)$ & $845.976^{* * *}$ & 0.000 & $(759.759 ; 932.194)$ \\
\hline LifeExp & -1.478 & 0.458 & $(-5.400 ; 2.443)$ & & & \\
\hline Poverty & -0.427 & 0.432 & $(-1.499 ; 0.644)$ & & & \\
\hline SpecDoctor & $39.205^{* *}$ & 0.036 & $(2.600 ; 75.810)$ & $34.857^{* *}$ & 0.021 & $(5.287 ; 64.426)$ \\
\hline PrimDoctor & $84.681^{*}$ & 0.077 & $(-9.427 ; 178.789)$ & $51.236^{* *}$ & 0.043 & $(1.613 ; 100.860)$ \\
\hline PrimNurs & -27.101 & 0.612 & $(-132.319 ; 78.116)$ & & & \\
\hline OperTheat & $-9.929^{* *}$ & 0.019 & $(-18.234 ;-1.624)$ & $-9.919^{* * *}$ & 0.010 & $(-17.428 ;-2.409)$ \\
\hline CTEquip & $67.632^{* * *}$ & 0.000 & $(32.275 ; 102.988)$ & $50.344^{* * *}$ & 0.001 & $(22.034 ; 78.655)$ \\
\hline HospAdm & -0.183 & 0.602 & $(-0.875 ; 0.509)$ & & & \\
\hline HospStay & $-38.914^{* * *}$ & 0.000 & $(-56.237 ;-21.591)$ & $-29.568^{* * *}$ & 0.000 & $(-43.567 ;-15.569)$ \\
\hline OutpSurg & -0.437 & 0.258 & $(-1.195 ; 0.322)$ & & & \\
\hline UseCT & -0.272 & 0.253 & $(-0.741 ; 0.197)$ & & & \\
\hline UseHemod & $0.729^{* * *}$ & 0.004 & $(0.232 ; 1.226)$ & $0.666^{* * *}$ & 0.002 & $(0.246 ; 1.086)$ \\
\hline HospInfec & -0.500 & 0.979 & $(-38.732 ; 37.731)$ & & & \\
\hline InHospMort & $11.392^{*}$ & 0.097 & $(-2.082 ; 24.865)$ & $8.589^{*}$ & 0.086 & $(-1.233 ; 18.412)$ \\
\hline Expend & -0.016 & 0.394 & $(-0.054 ; 0.021)$ & & & \\
\hline ExpPharm & $-4.796^{* * *}$ & 0.000 & $(-6.981 ;-2.611)$ & $-4.290^{* * *}$ & 0.000 & $(-6.016 ;-2.565)$ \\
\hline Observations & 187 & & & 187 & & \\
\hline$R^{2}$ & 55.4 & & & 53.4 & & \\
\hline Adjust $R^{2}$ & 51.2 & & & 51.3 & & \\
\hline ANOVA & $13.179^{* * *}$ & 0.000 & & $25.504^{* * *}$ & 0.000 & \\
\hline Durbin-Watson & 1.734 & & & 1.732 & & \\
\hline
\end{tabular}

$* * * * *$ and $*$ indicate a significance of less than $1 \%$, less than $5 \%$ and less than $10 \%$, respectively.

Table 6 Women's satisfaction: regression analysis (OLS estimation)

\begin{tabular}{|c|c|c|c|c|c|c|}
\hline \multirow{2}{*}{ Variables } & \multicolumn{3}{|c|}{ Enter method } & \multicolumn{3}{|c|}{ Backward method } \\
\hline & B & $p$ & Confidence interval & B & $p$ & Confidence interval \\
\hline Constant & $1,255.667^{k+k *}$ & 0.000 & $(720.65 I ; ।, 790.684)$ & $862.045^{* * * k}$ & 0.000 & $(774.773 ; 949.318)$ \\
\hline Poverty & -0.284 & 0.607 & $(-1.372 ; 0.804)$ & & & \\
\hline PrimNurs & -23.553 & 0.646 & $(-124.472 ; 77.366)$ & & & \\
\hline OperTheat & $-12.485^{\text {*ik }}$ & 0.002 & $(-20.399 ;-4.572)$ & $-10.873^{* * *}$ & 0.004 & $(-18.160 ;-3.586)$ \\
\hline CTEquip & $72.623^{\text {*adk }}$ & 0.000 & $(38.730 ; 106.516)$ & $71.494^{\text {**** }}$ & 0.000 & $(43.828 ; 99.161)$ \\
\hline UseCT & $-0.488^{* *}$ & 0.032 & $(-0.932 ;-0.043)$ & $-0.545^{* k * k}$ & 0.006 & $(-0.930 ;-0,159)$ \\
\hline UseHemod & $0.770^{\text {*wok }}$ & 0.002 & $(0.297 ;$ । .244$)$ & $0.824^{\text {*owk }}$ & 0.000 & $(0.410 ; 1.238)$ \\
\hline
\end{tabular}

Citation: Martínez MDCV, Oller IMP. Health investment management based on patient satisfaction with the primary care doctor in the Spanish national health service context. a gender perspective. MOJ Gerontol Ger. 2019;4(5):204-2II. DOI: I0.15406/mojgg.2019.04.00208 
Table continued...

\begin{tabular}{|c|c|c|c|c|c|c|}
\hline \multirow{2}{*}{ Variables } & \multicolumn{3}{|c|}{ Enter method } & \multicolumn{3}{|c|}{ Backward method } \\
\hline & B & $p$ & Confidence interval & B & $p$ & Confidence interval \\
\hline Hosplnfec & -9.843 & 0.600 & $(-46.878 ; 27.192)$ & & & \\
\hline InHospMort & $15.773^{* *}$ & 0.014 & $(3.193 ; 28.353)$ & $14.369^{* * * *}$ & 0.008 & $(3.784 ; 24.955)$ \\
\hline Expend & $-0.038^{* *}$ & 0.036 & $(-0.073 ;-0.003)$ & -0.044 & 0.006 & $(-0.075 ;-0.013)$ \\
\hline ExpPharm & $-5.622^{\text {k }}$ & 0.000 & $(-7.695 ;-3.549)$ & $-5.006^{\text {ktok }}$ & 0.000 & $(-6.728 ;-3.284)$ \\
\hline Observations & 187 & & & 187 & & \\
\hline$R^{2}$ & 57.4 & & & 56.6 & & \\
\hline Adjust $R^{2}$ & 53.4 & & & 54.1 & & \\
\hline ANOVA & $14.315^{\text {*opk }}$ & 0.000 & & $22.917^{4 k * k}$ & 0.000 & \\
\hline Durbin-Watson & 1.734 & & & 1.861 & & \\
\hline
\end{tabular}

$* * *, * *$ and $*$ indicate a significance of less than I $\%$, less than $5 \%$ and less than $10 \%$, respectively

An increase in the number of doctors, both specialists and primary care, as well as an increase in the availability of CT equipment, explained positively the satisfaction of both sexes. Whereas, the variable number of operating theatres did so negatively.

On the other hand, the patient satisfaction with the primary care doctor was positively influenced by the increased use of haemodialysis equipment and negatively by the length of the hospital stay and the use of CT equipment.

In addition, patient satisfaction was directly related to the in hospital mortality rate, but inversely to the percentage of expenditure on pharmacy, that is, on medication.

The models presented are valid, as the $F$-test showed in the ANOVA analysis. In the models, there are no problems of colineality (tolerance levels and VIF were analysed, as well as the indexes of condition and the proportions of variance, whose values have been omitted in the tables for reasons of simplicity). There are also no problems of autocorrelation among residuals or heterocedasticity, as the DurbinWatson statistic (Tables $5 \& 6$ ) and the analysis of residuals showed.

\section{Discussion}

Health managers aim to achieve an effective NHS, which means meeting citizens' health requirements in a satisfactory way. As the resources available are scarce, they need information about which policies lead to a better assessment by users. So that satisfaction studies are an appropriate instrument for this. Knowing which variables have the greatest influence on satisfaction and how they do so allows establishing health policies that lead to a more favourable patient perception of the services.

Most of the current work on satisfaction focused on the relationship between patient and health care personnel, especially doctors and nurses, analysing variables such as the personal treatment received, the patient's involvement in decisions about his/her treatment, etc. ${ }^{6,41-}$ ${ }^{42}$ However, there are few studies aimed at NHS managers, as it is the case of the present paper. The analysis in this work focused on variables related to investments and health practice results (resources, expenditure, level of use and security), as well as welfare variables. These latter are also determined by the policies developed in the country.

The first conclusion obtained from this study is that women value, in general and on average, the services provided by the primary care doctor better than men. However, the factors that influence the evaluation are the same and with a similar weight in both sexes. That is, there are no different variables to consider in the valuation made by men and women. ${ }^{12,36}$

According to previous studies, ${ }^{11,25,43}$ resources available explain much of the patient satisfaction with the primary care doctor, especially the ratio of doctors, both in terms of the primary care doctor and the specialist doctor. In Spain, both the primary care doctor and the specialist doctor have computer access to the patient's medical history, share and exchange information. In addition, it is the family doctor who sends the patient to the specialist doctor and, in turn, the latter, once diagnosed and provided treatment, returns the patient to the family doctor for follow-up. This explains why the increased number of specialist doctors available positively influences the patient's satisfaction with the primary care doctor. In the light of the results of this work, we can state that a fundamental policy to be considered by managers is to increase medical personnel, as a quality measure that improves patient satisfaction.

The previous literature regarding the level of use of health services is varied, coinciding with the results of this study. In general, it is claimed that greater use implies greater satisfaction, ${ }^{37}$ as is the case with the use of haemodialysis equipment. However, the longer average hospital stay and the use of CT equipment, ${ }^{44}$ along with the number of operating theatres, reduce satisfaction. What can be a response to an unsatisfactory service. So that, dissatisfaction could be understood as a result of the need to continue using services that previously did not meet expectations..$^{23,45}$ The patient may also assume that a longer period of hospitalization or surgery may be the result of a delay by the primary care doctor in sending the patient to hospital or a prior treatment not suited to his condition. With regard to the use of CT equipment, we can mention the fear of many patients to be diagnosed, due to the claustrophobia that the equipment produces.

The increase of in-hospital mortality positively influences patient satisfaction, which is consistent with previous studies showing that the greater the risk of death, the greater the satisfaction the patient showed towards services received. ${ }^{37,45}$ It may also be inferred that, in general, citizens prefer their relatives to be cared for in a hospital until their death, with the appropriate means and care that only the hospital can provided.

An inverse relationship was found between the proportion of expenditure spent on medication and the patient satisfaction with the 
family doctor. This is consistent with previous literature, ${ }^{23,45}$ since a higher spending on medication increases satisfaction only in patients over 65 years of age. Therefore, younger patients should be provided with alternative therapies.

The research developed in this work provides relevant data on patient satisfaction with the primary care doctor, as it highlights some relevant factors affecting the citizen's perception as NHS user. The results obtained are useful information for the development of health policies by the managers of the NHS; in order to increase the valuation of the health care received by the patient. This is because this work has managed to explain up to $54.1 \%$ of the satisfaction.

The main limitation that we have found in the realization of this study was the availability of information. It would have been interesting to have the disaggregated data, instead of the averages of each autonomous community, as well as have evaluated the influence of other unavailable variables.

\section{Conclusion}

Women are more satisfied, on average, with the knowledge of the history and monitoring of their health problems by the primary care doctor in the Spanish NHS. Although the variables that influence their perception are the same as in men. In order to increase patient satisfaction and, therefore, quality of healthcare service, health policies should increase the number of doctors (specialist doctors and family doctors) as well as specialized treatment and diagnostic equipment, such as CT and hemodialysis equipment. Moreover, due to the fear of patients being diagnosed and treated with certain equipment, such as CT scans, information campaigns should be focused on this issue. Furthermore, health managers should provide enough resources to supply hospital treatment and primary care doctors should have no constraints to refer patients to the hospitals. Another aspect to consider is the monitoring of surgeries, which must be effective. Additionally, drug prescription should be moderated, what implies allocating resources to facilitate the use of alternative therapies.

\section{Acknowledgements}

None.

\section{Conflicts of interest}

The authors declare to have no conflict of interest.

\section{References}

1. Faezipour M, Ferreira S. A system dynamics perspective of patient satisfaction in healthcare. Procedia Comput Sci. 2013;16:148-56.

2. Ricci-Cabello I, Stevens S, Dalton ARH, et al. Identifying primary care pathways from quality of care to outcomes and satisfaction using structural equation modelling. Health Serv Res. 2018;53(1):430-449.

3. Vogus TJ, McClelland LE. When the customer is the patient: Lessons from healthcare research on patient satisfaction and service quality ratings. Human Resource Management Review. 2016;26(1):37-49.

4. Handayani PW, Hidayanto AN, Sandhyaduhita PI, et al. Strategic hospital services quality analysis in Indonesia. Expert Syst Appl. 2015;42(6):30673078 .

5. Aliman, NK, Mohamad. Linking service quality, patients' satisfaction and behavioral intentions: an investigation on private healthcare in Malaysia. Procedia Soc Behav Sci. 2016;224:141-148.
6. De Simone S, Planta A, Cicotto G. The role of job satisfaction, work engagement, self-efficacy and agentic capacities on nurses' turnover intention and patient satisfaction. Appl Nurs Res. 2018;39:130-140.

7. Díaz R. Satisfacción del paciente: principal motor y centro de los servicios sanitarios. Rev Calid Asist. 2002;17(1):22-29.

8. Maesala A, Paul J. Service quality, consumer satisfaction and loyalty in hospitals: Thinking for the future. Journal of Retailing and Consumer Services. 2018;40:261-269.

9. Pérez-Romero S, Gascón-Cánovas JJ, Salmerón-Martínez D, et al Sociodemographic characteristics and geographic variability associated with patient satisfaction in primary care. Rev Calid Asist. 2016;31(5):300 308.

10. Rebull J, Castellá M, De Pablo A, et al. Satisfacción de los usuarios de un servicio de urgencias: comparación de resultados. Rev Calid Asist. 2003;18(5):286-290.

11. Pérez-Romero S, Gascón-Cánovas JJ, Salmerón-Martínez D, et al. Relevance of the socioeconomic and health context in patient satisfaction. Gac Sanit. 2017;31(5):416-422.

12. Jaráiz E, Lagares N, Pereira M. The components of patient satisfaction and their usefulness for hospital management. Revista Española de Ciencia Política. 2013;32:161-181.

13. Chang CW, Tseng TH, Woodside, A. Configural algorithms of patient satisfaction, participation in diagnostics, and treatment decisions' influences on hospital loyalty. Journal of Services Marketing. 2013;27(2):91-103.

14. Fernández-Martín LC, Iglesias-de-Sena H, Fombellida-Velasco C, et al. Patient satisfaction as a quality indicator in mental health. Rev Calid Asist. 2016;31(5):254-261.

15. Dávila FA, Herrera JS, Yasnó DA, et al. Satisfaction according to health care insurance systems in an emergency department. Rev Calid Asist. 2017;32(2):89-96.

16. García-Lacalle J, Martin E. Rural vs urban hospital performance in a competitive public health service. Social Science \& Medicine. 2010;71(6):1131-1140.

17. De la Fuente-Rodríguez A, Fernández-Lerones MJ, Hoyos-Valencia Y, et al. Primary care urgent service. Study of patient preceived quality and satisfaction in the Altamira health (Spain) catchment area. Rev Calid Asist. 2009;24(3):109-114.

18. Correia SM, Miranda FJ. Quality and satisfaction in hospitable urgencies service: Analysis of a Portugal center zone hospital. Investigaciones Europeas de Dirección y Economía de la Empresa. 2010;16(2):27-41.

19. Caminal, J. La medida de la satisfacción: un instrumento de participación de la población en la mejora de la calidad de los servicios sanitarios. Rev Calid Asist. 2001;16:276-279.

20. Yang H, Guo X, Wu T. Exploring the influence of the online physician service delivery process on patient satisfaction. Decision Support Systems. 2015;78:113-121.

21. Arrazola-Vacas M, Hevia-Payá J, Rodríguez-Esteban L. What factors help to explain satisfaction with Primary Health care in Spain?. Rev Calid Asist. 2015;30(5):226-236.

22. Draper M, Cohen P, Buchan H. Seeking consumer views: what use are results of hospital patient satisfaction surveys?. Int J Qual Health Care. 2001;13(6):463-468.

23. Pascoe, GC. Patient satisfaction in primary health care: a literatura review and analysis. Eval Program Plann. 1983;6(3-4):185-210. 
24. Gómez-Payo S, Del Río-Moro O, Manrique-García A, et al. User satisfaction in the virgen del valle geriatric hospital, Toledo. Rev Calid Asist. 2012;27(2):78-84.

25. Serrano-Del-Rosal R, Galiano-Coronil S, Ranchal-Romero J. Diseccionando la satisfacción de los usuarios con los servicios de atención hospitalaria del sistema sanitario público andaluz. Praxis Sociológica. 2014;18:101-116.

26. Bleich S, Özaltin E, Murray CJL. How does satisfaction with the healthcare system relate to patient experience?. Bull World Health Organ. 2009;87:271-278.

27. Thornton RD, Nurse N, Snavely L, et al. Influences on patient satisfaction in healthcare centers: a semi-quantitative study over 5 years. BMC Health Serv Res. 2017;17:1-9.

28. García-Alfranca F, Puig A, Galup C, et al. Patient satisfaction with prehospital emergency services. a qualitative study comparing professionals' and patients' views. Int J Environ Res Public Health. 2018;15(2):1-31

29. Kitapci O, Akdogan C, Dortyol,IT. The impact of service quality dimensions on patient satisfaction, repurchase intentions and word-ofmouth communication in the public healthcare industry. Procedia Soc Behav Sci. 2014:148:161-169.

30. Ramírez-Sánchez T, Nájera-Aguilar P, Ningenda-López G. Users perception about of quality ambulatory healthcare services in Mexico. Salud Publica Mex. 1998;40(1):1-10.

31. Quintana JM, González N, Bilbao A, Aizpuru F, Escobar A, Esteban C et al. Predictors of patient satisfaction with hospital health care. BMC Health Serv Res. 2006;6:1-9.

32. Mira JJ, Aranaz, J. Patient satisfaction as a measure of health care outcome. Med Clin. 2000;114(3):26-33

33. González N, Quintana JM, Bilbao A, et al. Patient satisfaction in four hospitals of the basque health service. Gac San. 2008;22(3):210-217.

34. Taqdees F, Shahab AM, Asma S. Hospital healthcare service quality, patient satisfaction and loyalty. International Journal of Quality \& Reliability Management. 2018;35(6):1194-1214.
35. Añel-Rodríguez RM, Cambero-Serrano MI, Irurzun-Zuazabal, E Analysis of patient complaints in Primary Care: An opportunity to improve clinical safety. Rev Calid Asist. 2015;30(5):220-225.

36. Parra P, Bermejo RM, Más A, Hidalgo MD, Gomis R, Calle JE. Factors related to patient satisfaction with hospital emergency services. Gac Sanit. 2012;26(2):159-165.

37. Fenton JJ, Jerant AF, Bertakis Kd, et al. The cost of satisfaction: a national study of patient satisfaction, health care utilization, expenditures, and mortality. Arch Intern Med. 2012;172(5):405-411.

38. Valls MC. Profitability, Corporate social responsibility and gender in private healthcare in spain. Rev Esp Invest Sociol. 2019;168:111-128.

39. Valls MC, Cruz S. Women on corporate boards and firm's financial performance. Womens Stud Int Forum. 2019;76:102251.

40. Valls MC, Cruz S, Parra IM. Gender policies on board of directors and sustainable development. Corp Soc Responsib Environ Manag. 2019:115 .

41. Yeh MY, Wu SC, Tung TH. The relation between patient education, patient empowerment and patient satisfaction: A cross-sectional-comparison study. Appl Nurs Res. 2018;39:11-17.

42. Aiken LH, Sloane DM, Ball J, et al. Patient satisfaction with hospital care and nurses in England: an observational study. BMJ open. 2018;8(1):1-8.

43. Amin M, Nasharuddin SZ. Hospital service quality and its effects on patient satisfaction and behavioural intention. Clin Gonv. 2013;18(3):238-254.

44. Morales JM, Bonill C, Celdrán M, et al. Design and validation of a home care satisfaction questionnaire: SATISFAD. Gac Sanit. 2007;21(2):106113.

45. Valls MC, Abad E. Patient satisfaction in the spanish national health system. An Sist Sanit Navar. 2018;41(3):309-320. 